\title{
Does Herpes Virus Reactivation Affect Prognosis in Idiopathic Sudden Sensorineural Hearing Loss?
}

\author{
Sang Man Park · Chun Han · Jae Woo Lee $\cdot$ Tae Hoon Kong $\cdot$ Young Joon Seo \\ Department of Otorhinolaryngology, Yonsei University Wonju College of Medicine, Wonju, Korea
}

Objectives. Several etiologies have been proposed to underlie idiopathic sudden sensorineural hearing loss (ISSNHL), including viral infection, vascular disturbance, and immune-mediated mechanisms. However, none of these mechanisms are conclusive. Should ISSNHL be caused by reactivation of a viral infection, antiviral treatment would be an important option. Thus, in this study, we reported the prognosis according to serologic test results of herpes viruses in patients with ISSNHL. We also evaluated treatment response with acyclovir and corticosteroids versus corticosteroids alone in herpes simplex virus (HSV) seropositive ISSNHL patients.

Methods. We compared hematologic examinations and the results of audiometry testing in 232 patients with ISSNHL. Statistical analyses for initial hearing impairment, progression of hearing impairment, recovery of hearing loss, and laboratory results were performed in all patients. All statistical analyses were performed using SPSS software.

Results. The 232 ISSNHL patients were divided into two subgroups according to HSV immunoglobulin M (IgM) serologic results (seropositive or seronegative). When the seropositive group was compared to the seronegative group, age, gender, body mass index (BMI), white blood cell, absolute neutrophil count, absolute monocyte count, and platelet count were not significantly different. Initial hearing level, final recovery hearing level, and recovery time were also not significantly different between the two groups $(P>0.05)$. Though there were no significant differences in age, gender, BMI, or viral HSV IgM titer, the two groups had similar initial hearing level, final recovery hearing level, and recovery time. The difference in hearing threshold before and after treatment was larger $(18.7 \pm 37.1)$ in the group receiving antiviral medication than in the corticosteroids group (11.0 \pm 44.5$)$, but this difference was not significant $(P=0.619)$.

Conclusion. There was no significant difference of prognosis between the patients with and without reactivation of HSV. In addition, there seems to be no benefit for the treatment of acyclovir combined with the corticosteroids in the patients with ISSNHL.

Keywords. Sudden Hearing Loss; Prognosis; Herpes Simplex Virus; Reactivation; Acyclovir

\section{INTRODUCTION}

Idiopathic sudden sensorineural hearing loss (ISSNHL) is defined as a hearing loss over $30 \mathrm{~dB}$ in three contiguous frequencies in less than 3 days [1]. The causes of ISSNHL remain un-

- Received March 9, 2016

Revised May 26, 2016

Accepted June 9, 2016

- Corresponding author: Young Joon Seo

Department of Otorhinolaryngology, Yonsei University Wonju College of

Medicine, 20 Ilsan-ro, Wonju 26426, Korea

Tel: +82-33-741-0644, Fax: +82-33-732-8287

E-mail: okas2000@hanmail.net known yet, but various hypotheses might be from viral infection, immune-medicated mechanisms, and vascular disturbance. Since Van Dishoeck and Bierman [2] had suggested a possibility of viral involvement for ISSNHL in 1957, this has been supported by studies of seroconversion of viral antibody titers in patients with ISSNHL. In addition, herpetic viral labyrinthitis showed a histopathologic pattern of cochlear damage that matched those of patients with ISSNHL [3]. Experimentally-induced labyrinthitis by herpes simplex virus (HSV) resulted in sudden hearing loss in guinea pigs, and the cochlear histopathologic findings also closely resembled those seen in ISSNHL [4]. The hypothesis that ISSNHL is caused by reactivation of viral

Copyright ( $) 2017$ by Korean Society of Otorhinolaryngology-Head and Neck Surgery.

This is an open-access article distributed under the terms of the Creative Commons Attribution Non-Commercial License (http://creativecommons.org/licenses/by-nc/4.0)

which permits unrestricted non-commercial use, distribution, and reproduction in any medium, provided the original work is properly cited. 
infection made an antiviral treatment to be an important option in treatments of ISSNHL.

In this study, we report whether the result of serologic testing for herpes viruses in patients with ISSNHL affects a prognosis of the disease, and we evaluated the efficacy of treatment with acyclovir and corticosteroids versus corticosteroids alone in ISSNHL patients with HSV seropositivity.

\section{MATERIALS AND METHODS}

\section{Patients}

In this retrospective data analysis, we reviewed 1,046 ISSNHL patients treated in Department of Otorhinolaryngology in Yonsei University Wonju College of Medicine from 2009 to 2013. We defined ISSNHL as acute unilateral deafness with an abrupt onset (generally within 3 days), with greater than $30 \mathrm{~dB}$ of hearing loss at three consecutive frequencies. Patient inclusion criteria for this study were as follows: presented within 1 week of onset, no previous steroid treatment, available blood samples (including herpes viral titers) that were collected prior to treatment, pure tone hearing tests performed at the first visit, and no abnormal findings that might suggest a cause of the hearing loss on magnetic resonance imaging. Patients were excluded from the study if they had any otologic disease such as chronic otitis media, otosclerosis, history of acoustic trauma, or Meniere's disease. Ultimately, we included 232 patients in this study. No patients reported recent herpes labialis relapses. Patients were generally discharged 5-7 days after admission and underwent clinical follow-up for 2 months. All patients were treated with $1 \mathrm{mg} /$ $\mathrm{kg}$ per day of prednisone, followed by a dose taper. In patients whose laboratory results showed viral seropositivity within 7 days after admission, acyclovir treatment was added for 10 days. Otherwise, steroid therapy alone was continued. However, some patients with viral seropositivity missed the treatment with antiviral medication.

\section{Hematologic examinations}

Blood samples were tested for all patients at the first visit in order to identify high-risk patients, such as those with diabetes mellitus, to prevent adverse effects of the steroid treatment.
Complete blood count (CBC) and routine chemistry panels were also collected. An automated blood cell counter was used for CBC measurements (Sysmex XE-2100, Sysmex, Kobe, Japan). The detection of immunoglobulin G (IgG) and IgM to herpes simplex virus 1 (HSV-1), HSV-2, and varicella zoster virus (VZV) was performed using enzyme-linked immunosorbent assay (ELISA).All samples were run in duplicate, and the mean values were used for statistical analysis.

\section{Auditory evaluation}

Pure tone thresholds were obtained for air conduction at 250 $\mathrm{Hz}, 500 \mathrm{~Hz}, 1 \mathrm{kHz}, 2 \mathrm{kHz}, 4 \mathrm{kHz}$, and $8 \mathrm{kHz}$ and for bone conduction at $250 \mathrm{~Hz}, 500 \mathrm{~Hz}, 1 \mathrm{kHz}, 2 \mathrm{kHz}$, and $4 \mathrm{kHz}$. Audiologic data were reported according to the methods recommended by the Hearing Committee of the American Academy of Otolaryngology Head and Neck Surgery. Patients were evaluated according to the recovery observed in the 2-month follow-up period. Pure tone audiometry (PTA) was performed based on patient responses to treatment, and the results were classified according to Siegel's criteria (Table 1) [5-7]. The patients were then divided into two groups classified as recovered (complete+ partial+slight) and unrecovered (no improvement). The first recovery time indicates the time of initial hearing recovery according to Siegel's criteria [7]. The final recovery time was noted as the duration to the final follow-up.

\section{Statistical analysis}

A power analysis was performed to determine if the proposed sample size would be adequate (effect size $=0.062, \alpha$-risk $=0.05$, sample size $=222$ ). Continuous variables were summarized as mean \pm standard deviation (SD). Comparisons between continuous variables were performed using Student $t$-test. Categorical variables were summarized as percentages of the group total, and comparisons between groups were analyzed using either Fisher exact test or chi-square test where appropriate. Assessment of the bivariate relationship between recovery and viral titer was performed using data from 232 patients. A $P$-value of 0.05 was set as the threshold for significance for all tests. All statistical analyses were performed using PASW ver. 18.0 (SPSS Inc., Chicago, IL, USA).

\section{RESULTS}

The results of the serologic screening tests are summarized in Table 2. Of the 232 patients tested for herpes simplex andVZVs, HSV-1 IgG titer was increased in $45.7 \%$, which is consistent with the reported prevalence of long-term herpes infection. The presence of HSV IgM indicates acute herpes reactivation, and HSV IgM was positive in 33 of 232 patients $(14.2 \%)$. VZV screening was performed as well (IgG positive, $90.5 \%$ and IgM positive, $4.3 \%$ ). 
Table 1. Siegel's criteria of hearing improvement

\begin{tabular}{lll}
\hline Type & & \multicolumn{1}{c}{ Hearing recovery } \\
\hline I & Complete recovery & Patients whose final hearing level is better than $25 \mathrm{~dB}$ regardless of the size of the gain \\
II & Partial recovery & Patients who show more than $15 \mathrm{~dB}$ of gain and whose final hearing level is between 25 and $45 \mathrm{~dB}$ \\
III & Slight recovery & Patients who show more than $15 \mathrm{~dB}$ of gain and whose final hearing level is poorer than $45 \mathrm{~dB}$ \\
IV & No improvement & Patients who show less than $15 \mathrm{~dB}$ of gain \\
\hline
\end{tabular}

Table 2. Serologic screening test results $(n=232)$

\begin{tabular}{lc}
\hline Serologic test & ISSNHL, positive (\%) \\
\hline HSV 1 lgG & $106(45.7)$ \\
HSV 2 lgG & $45(19.4)$ \\
HSV IgM & $33(14.2)$ \\
VZV IgG & $210(90.5)$ \\
VZV IgM & $10(4.3)$ \\
\hline
\end{tabular}

ISSNHL, idiopathic sudden sensorineural hearing loss; HSV, herpes simplex virus; IgG, immunoglobulin G; IgM, immunoglobulin M; VZV, varicella zoster virus.

Table 3. Patient demographic characteristics according to serologic test results

\begin{tabular}{lccc}
\hline Variable & $\begin{array}{c}\text { Seropositive } \\
(\mathrm{n}=33)\end{array}$ & $\begin{array}{c}\text { Seronegative } \\
(\mathrm{n}=198)\end{array}$ & $P$-value \\
\hline Age $(\mathrm{yr})$ & $54 \pm 19$ & $52 \pm 15$ & 0.564 \\
Gender (male:female) & $12: 21$ & $111: 87$ & 0.040 \\
Body mass index $\left(\mathrm{kg} / \mathrm{m}^{2}\right)$ & $23.5 \pm 4.5$ & $24.5 \pm 3.9$ & 0.237 \\
Viral titer $(\mathrm{HSV}$ IgM) & $1,047 \pm 1,389$ & $161 \pm 103$ & 0.000 \\
Affected ear $($ right:left $)$ & $16: 17$ & $81: 117$ & 0.450 \\
Initial hearing level $(\mathrm{dB})$ & $69.1 \pm 31.0$ & $62.5 \pm 29.8$ & 0.262 \\
Final recovery hearing level $(\mathrm{dB})$ & $39.2 \pm 34.0$ & $36.7 \pm 28.8$ & 0.683 \\
First recovery time $($ day $)$ & $18.1 \pm 37.1$ & $11.8 \pm 15.8$ & 0.410 \\
Final recovery time $($ day) & $68.9 \pm 115.4$ & $61.9 \pm 109.5$ & 0.747 \\
Dizziness, yes & $4(12)$ & $38(19)$ & 0.645 \\
Hemoglobin $\left(10^{3} / \mu \mathrm{L}\right)$ & $13.3 \pm 1.6$ & $13.5 \pm 1.3$ & 0.046 \\
WBC $\left(10^{3} / \mu \mathrm{L}\right)$ & $8.3 \pm 3.0$ & $8.2 \pm 3.2$ & 0.305 \\
Neutrophil $\left(10^{3} / \mu \mathrm{L}\right)$ & $6.1 \pm 2.3$ & $5.8 \pm 3.4$ & 0.623 \\
Lymphocyte $\left(10^{3} / \mu \mathrm{L}\right)$ & $1.7 \pm 0.9$ & $1.7 \pm 0.8$ & 0.620 \\
Monocyte $\left(10^{3} / \mu \mathrm{L}\right)$ & $0.3 \pm 0.2$ & $0.4 \pm 0.2$ & 0.979 \\
Platelet $\left(10^{3} / \mu \mathrm{L}\right)$ & $252.4 \pm 66.9$ & $251.2 \pm 49.7$ & 0.738 \\
\hline
\end{tabular}

Values are presented as number (\%) or mean \pm standard deviation. HSV, herpes simplex virus; IgM, immunoglobulin M; WBC, white blood cell.

The 232 ISSNL patients were divided into two subgroups according to HSV IgM serology (seropositive and seronegative). When the seropositive group was compared to the seronegative group, age, gender, body mass index (BMI), white blood cell (WBC), absolute neutrophil count, absolute monocyte count, and platelet count were not significantly different (Table 3). Initial hearing level, final recovery hearing level, and recovery time were also not significantly different between groups $(P>0.05)$. Fig. 1 shows the hearing thresholds at each frequency in initial and final PTAs in the seropositive and seronegative groups.

Among the 33 HSV IgM seropositive patients, 11 received antiviral treatment. To evaluate the effects of antiviral treatment
Table 4. Patient demographic characteristics according to different treatments

\begin{tabular}{|c|c|c|c|}
\hline Variable & $\begin{array}{c}\text { Anti-viral }(+) \\
(n=11)\end{array}$ & $\begin{array}{l}\text { Anti-viral }(-) \\
(n=22)\end{array}$ & $P$-value \\
\hline Age (yr) & $59 \pm 13$ & $51 \pm 22$ & 0.201 \\
\hline Gender (male:female) & $3: 8$ & $9: 13$ & 0.425 \\
\hline Body mass index $\left(\mathrm{kg} / \mathrm{m}^{2}\right)$ & $24.7 \pm 3.3$ & $22.9 \pm 4.9$ & 0.237 \\
\hline Viral titer (HSV IgM) & $881.8 \pm 582.5$ & $810.6 \pm 471.1$ & 0.739 \\
\hline Affected ear (right:left) & $5: 6$ & $11: 11$ & 0.945 \\
\hline Initial hearing level $(\mathrm{dB})$ & $80.5 \pm 23.2$ & $65.7 \pm 32.9$ & 0.157 \\
\hline Average final recovery rate (\%) & $62.5 \pm 46.5$ & $58.1 \pm 54.3$ & 0.817 \\
\hline Final recovery hearing level $(\mathrm{dB})$ & $40.5 \pm 29.5$ & $39.8 \pm 36.8$ & 0.819 \\
\hline First recovery time (day) & $11.3 \pm 12.4$ & $21.4 \pm 45.7$ & 0.418 \\
\hline Final recovery time (day) & $87.8 \pm 169.1$ & $62.4 \pm 87.8$ & 0.663 \\
\hline Gap of hearing thresholds $(\mathrm{dB})$ & $18.7 \pm 37.1$ & $11.0 \pm 44.5$ & 0.619 \\
\hline
\end{tabular}

Values are presented as number or mean \pm standard deviation.

HSV, herpes simplex virus; IgM, immunoglobulin M.

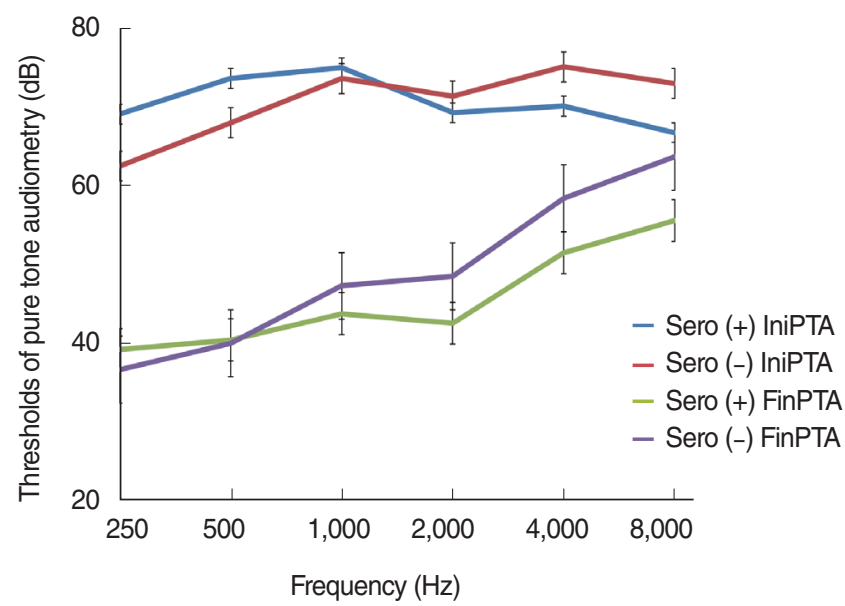

Fig. 1. The changes of hearing thresholds after the treatment of idiopathic sudden sensorineural hearing loss in seropositive (+) and seronegative (-) groups. There were no significant differences between the groups in initial hearing, final hearing, and gaps of initialfinal hearing. PTA, pure tone audiometry; IniPTA, initial PTA; FinPTA, final PTA.

on ISSNHL patients with HSV IgM seropositivity, we compared the patients who received antiviral treatment to those who did not undergo treatment (Table 4). There were no significant differences in age, gender, BMI, or viral HSV IgM titer between the two groups, and the two groups had similar initial hearing level, final recovery hearing level, and recovery time. The difference in hearing threshold before and after treatment was greater $(18.7 \pm$ 
37.1) in the group that received antiviral medication than in the group that did not (11.0 \pm 44.5$)$, but this difference was not significant $(P=0.619)$.

We performed the bivariate relationships between recovery indicators (initial hearing level, final hearing level, difference in hearing threshold, and recovery duration) and viral titer. However, there were no correlations between these variables $(P>0.05)$.

\section{DISCUSSION}

Because there have been no definite causes of ISSNHL, there is no standardized treatment protocol for patients with ISSNHL. At this point of time, antiviral medication for treatment of ISSNHL is a controversial topic in the literature [8]. A viral cause, based on a positive study for viral infections, has been hypothesized in about $35 \%$ of ISSNHL cases [9]. Vasama and Linthicum [10] proposed a viral etiology of ISSNHL using histological data. In addition, the induction experiment of a labyrinthitis process in guinea pigs by HSV-1 also showed the similar histopathology findings for ISSNHL [4]. However, to our knowledge, there have been no well-organized studies for the prognoses in patients with seropositive titers of those viruses. The previous studies showed the usefulness of antiviral medication just in sudden hearing loss patients with idiopathic causes [3,5]. We believe this study, which evaluates serologic tests for herpes viruses in patients with ISSNHL and compares prognoses according to treatment with acyclovir and corticosteroids versus corticosteroids alone in HSV IgM seropositive patients, is quite meaningful.

In the literature, a seropositive antibody to HSV-1 was found in $80 \%$ of patients and $77 \%$ of controls, the difference between which was not significant [11]. Gagnebin and Maire [12] reported in 106 patients tested for HSV and VZV that IgG titer was increased in $63 \%$, and all tested patients had normal IgM titer. In that study, the ratio of HSV-1 IgG seropositivity in patients with ISSNHL was $45.7 \%$. When considering HSV and VZV IgG, the percentages of infection were consistent with other references $[11,13]$. We found HSV IgM seropositivity to be $14.2 \%$. This value is meaningful in regard to acute viral reactivation. In order to study the role of HSV-1 in the induction of ISSNHL, it is important to establish reliable treatment criteria. Thus, we decided to use HSV IgM status as a criterion to separate patients into seropositive and seronegative subgroups. Virologic diagnosis is usually carried out through direct or indirect techniques. Direct technique detects the virus at its site of infection, and indirect technique evaluates the host immunological response for the infection based on titration of specific antibodies. Because direct diagnosis of HSV is impossible for the invasiveness of the sampling, an indirect diagnosis is often established based on the detection of $\mathrm{M}$ class antibodies in order to identify a primary in- fection. In herpes viral infection, IgM is induced by an endogenous reinfection in most cases [14].

According to the literature, improvement in $81 \%$ of ISSNHL patients with high specific IgA titers was seen when acyclovir monotherapy was used $[15,16]$. In contrast to the literature, we observed no significant differences in outcome between HSV IgM seropositive and seronegative ISSNHL patients. Notably, the groups had no differences in age, gender, BMI, initial hearing level, or blood test results ( $\mathrm{Hb}, \mathrm{WBC}$, etc.). In addition, the two groups had similar recovery hearing thresholds $(39.24 \pm 33.96$ vs. $36.67 \pm 28.80, P=0.683)$ and similar recovery durations ( $68.85 \pm 115.4$ vs. $61.86 \pm 109.5, P=0.747)$. The shape of the audiogram did not show any specific findings to characterize the severity or location of the cochlear damage between the groups (Fig. 1). Therefore, we could not correlate viral titer with recovery of hearing loss.

In the ISSNHL patients with viral reactivation, we did not see any beneficial effects of combining acyclovir with prednisolone. We compared the combination treatment with acyclovir in the 33 patients who were HSV IgM seropositive. The patients receiving acyclovir and prednisolone treatment had no better hearing recovery than the patients receiving only prednisolone. Consistent with our results, Westerlaken et al. [17] also reported that the addition of acyclovir to corticosteroid therapy could not improve hearing recovery compared to corticosteroid therapy alone in a prospective, randomized, double-blind, placebo-controlled, multicenter trial. They studied the therapeutic value of acyclovir on hearing recovery in 91 patients with ISSNHL over a 1-year follow-up period. The placebo group showed greater recovery after 1 year than did the acyclovir group, but the difference of $6.6 \mathrm{~dB}$ was not statistically significant. In our study, although this study was a retrospective study, the evaluation was conducted only in patients with HSV reactivation. More largescale studies will be needed to provide a better understanding of ISSNHL and to offer information on more effective treatments. Our finding that even patients with viral reactivation showed no benefit from acyclovir treatment demonstrates that this treatment approach is unnecessary in ISSNHL patients.

In conclusion, there was no significant difference of prognosis between the patients with and without reactivation of HSV. In our study, although the combination of acyclovir and steroids is the preferred treatment for known herpetic infections, there seems to be no benefit of acyclovir in the treatment of ISSNHL. We suggest that clinicians do not need to give attention to the serologic results of HSV for planning the treatments of ISSNHL.

\section{CONFLICT OF INTEREST}

No potential conflict of interest relevant to this article was reported. 


\section{REFERENCES}

1. Hughes GB, Freedman MA, Haberkamp TJ, Guay ME. Sudden sensorineural hearing loss. Otolaryngol Clin North Am. 1996 Jun;29(3): 393-405.

2.Van Dishoeck HA, Bierman TA. Sudden perceptive deafness and viral infection: report of the first one hundred patients. Ann Otol Rhinol Laryngol. 1957 Dec;66(4):963-80.

3. Furuta Y,TakasuT, Fukuda S, InuyamaY, Sato KC, Nagashima K. Latent herpes simplex virus type 1 in human vestibular ganglia. Acta Otolaryngol Suppl. 1993;503:85-9.

4. Stokroos RJ, Albers FW, Schirm J.The etiology of idiopathic sudden sensorineural hearing loss: experimental herpes simplex virus infection of the inner ear.Am J Otol. 1998 Jul;19(4):447-52.

5. Siegel LG. The treatment of idiopathic sudden sensorineural hearing loss. Otolaryngol Clin North Am. 1975 Jun;8(2):467-73.

6.WilsonWR, Byl FM, Laird N. The efficacy of steroids in the treatment of idiopathic sudden hearing loss: a double-blind clinical study. Arch Otolaryngol. 1980 Dec;106(12):772-6.

7. Chang DS, Park SW, Choi JY, Kim AY, Park KY, Cho CS, et al. Estimate hearing recovery rate using statistical analysis of sudden sensorineural hearing loss. Korean J Otorhinolaryngol-Head Neck Surg. 2011 Sep;54(9):603-9.

8. Mattox DE, Lyles CA. Idiopathic sudden sensorineural hearing loss Am J Otol. 1989 May;10(3):242-7.

9. Yoshida Y, Yamauchi S, Shinkawa A, Horiuchi M, Sakai M. Immunological and virological study of sudden deafness. Auris Nasus Lar- ynx. 1996;23:63-8.

10. Vasama JP, Linthicum FH Jr. Idiopathic sudden sensorineural hearing loss: temporal bone histopathologic study. Ann Otol Rhinol Laryngol. 2000 Jun;109(6):527-32.

11. Koide J, Yanagita N, Hondo R, Kurata T. Serological and clinical study of herpes simplex virus infection in patients with sudden deafness. Acta Otolaryngol Suppl. 1988;456:21-6.

12. Gagnebin J, Maire R. Infection screening in sudden and progressive idiopathic sensorineural hearing loss: a retrospective study of 182 cases. Otol Neurotol. 2002 Mar;23(2):160-2.

13. Schulz P, Arbusow V, Strupp M, Dieterich M, Rauch E, Brandt T. Highly variable distribution of HSV-1-specific DNA in human geniculate, vestibular and spiral ganglia. Neurosci Lett. 1998 Aug;252(2): 139-42.

14. Scalia G, Palermo CI, Maiolino L, Costanzo CM, Zappal D, Grillo C, et al. Detection of serum IgA to HSV1 and its diagnostic role in sudden hearing loss. New Microbiol. 2013 Jan;36(1):41-7.

15. Schweinfurth JM, Parnes SM, Very M. Current concepts in the diagnosis and treatment of sudden sensorineural hearing loss. Eur Arch Otorhinolaryngol. 1996;253(3):117-21.

16. Lee HS, Lee YJ, Kang BS, Lee BD, Lee JS. A clinical analysis of sudden sensorineural hearing loss cases. Korean J Audiol. 2014 Sep;18 (2):69-75

17. Westerlaken BO, Stokroos RJ, Dhooge IJ, Wit HP, Albers FW. Treatment of idiopathic sudden sensorineural hearing loss with antiviral therapy: a prospective, randomized, double-blind clinical trial. Ann Otol Rhinol Laryngol. 2003 Nov;112(11):993-1000. 